\title{
Neoclassicism, critical realism and the Cambridge methodological tradition ${ }^{1}$
}

\author{
Sheila Dow \\ Published in J Morgan (ed.), What is neoclassical economics? \\ London: Routledge, 2015, pp. 102-18.
}

\begin{abstract}
The purpose of this paper is to consider Lawson's three-way classification of economics, whereby neoclassicism is defined in terms of inconsistency between ontology and methodology. The notion of classification is explored in order to consider Lawson's well-defined triad in relation to the more fluid, provisional, porous classifications within critical realist analysis itself. The difficulties with fitting economists into any one of the triad is illustrated by considering economics at Cambridge, not least because the methodology of individual figures is open to different interpretations. It is concluded that the main thrust of Lawson's argument is rhetorical, aimed at denting the insistence on mathematical modelling. His definition of neoclassical economics is directly relevant to new developments within the mainstream as well as to heterodox modellers, implying that the onus is on both to argue that modelling is justified in particular circumstances.
\end{abstract}

\author{
Division of Economics \\ University of Stirling \\ Stirling FK9 4LA \\ Scotland, UK \\ e-mail: $\underline{\text { s.c.dow@stir.ac.uk }}$ \\ and \\ Department of Economics, \\ University of Victoria \\ 3800 Finnerty Road \\ Victoria, BC V8P 5C2 \\ Canada
}

February 2015

\footnotetext{
${ }^{1}$ This chapter has benefitted from comments and suggestions from John Davis, Andrew Mearman and Jamie Morgan.
} 


\section{Introduction}

Tony Lawson (2013) has made a significant contribution by putting the category 'neoclassical' under the spotlight and by considering its relevance both for orthodox economics and for heterodox economics. The term has for a long time been applied generally to mainstream economics, but lately has not seemed a good fit, or is being used in very different ways, leading to its falling into relative disuse. Lawson's paper invites us to contemplate a specific use of the term (inspired by Veblen) and to consider how that meaning relates both to the mainstream and to heterodox economics. He concludes that the most useful configuration is three categories: orthodox economics, heterodox economics, and neoclassical economics which is in a state of tension between the first two. Lawson's focus continues to be to address the problems with mainstream economics: 'the real source of the discipline's problems is the very emphasis on mathematical modelling that defines the mainstream, an emphasis that usually results in formulations implicitly constrained to be consistent with a deficient social ontology' (Lawson 2013: 955). The particular motivation for attempting to clarify further categorisations is that 'the slack use of the category neoclassical economics hinders effective critique' (Lawson 2013: 956).

The classification draws on Lawson's distinction between closed and open systems applied to the subject matter and to its analysis: the underlying ontology and the methodology employed, respectively. Lawson's (1997) particular definition of a closed social system is that it is characterised by empirical regularities with respect to events. ${ }^{2}$ These regularities are the manifestations of uniformities which can be identified by deductive, axiomatic logic expressed in formal mathematical modelling. An open social system, on the other hand, is complex and evolving in a way which does not yield either axioms or laws which can be taken as universally true. Rather it consists of multiple causal tendencies which do not normally generate event regularities and whose character and interrelationships differ in time and space in a nondeterministic manner. Formal deductive mathematics is therefore an unsuitable methodology for analysing open systems, although some formal mathematical argument may contribute alongside other methods.

Lawson's (2013) categorisation of economics is defined in terms of these distinctions: orthodox economics professes a closed-system methodology, implying a closed-system ontology, while heterodox economics professes an open-system ontology and therefore an open-system methodology. Neoclassical economics involves the contradiction of an open-system ontology alongside a closed-system methodology. He argues,

'[T]he most coherent interpretation of neoclassical economics is of an inconsistent stance of 1) recognising the historical processual ontology of unfolding causal sequence at the level of events, whilst simultaneously 2) seeking to combine this recognition with a taxonomic orientation in the form of deductivism at the level of method that is inappropriate to it. That is, I suggest that interpreted most coherently, the category designates a deep tension, the very one that the currently loose usage of the term serves to mask' (Lawson 2013: 981)

\footnotetext{
${ }^{2}$ Chick and Dow (2005) offer a more general definition.
} 
If only this contradiction could be addressed, it is implied, economics could settle properly into a duality of orthodoxy/heterodoxy reflecting closed/open-system ontologies respectively. Of course, the critical realist argument includes a justification of the belief that social ontology must conform to an open system; the purpose of Lawson (1997) was therefore to point to the contradiction between the only justifiable (open-system) social ontology and the closed-system methodology of orthodox economics. Addressing this contradiction would require all of economics to employ an open-system methodology based on an open-system ontology.

The new focus on a contradiction between an open-system ontology and a closed-system methodology has particular relevance for new developments in mainstream economics which fall into Lawson's neoclassical category, making it clear in what sense they differ from heterodox economics. Behavioural economics is a case in point, where efforts are made to build on understanding of real behavioural processes, and yet the compulsion is to tailor this understanding to modifications to the traditional axiomatic structure (Dow 2013). Lawson (2009) has already pointed to the ontology-methodology inconsistency in well-meaning efforts to put forward alternative explanations of the crisis by developing alternative models (Lawson 2009). But compared with the contribution of Lawson's definition of neoclassical economics for our understanding of mainstream economics, the much more important and controversial argument in my view is that a significant portion of heterodox economics should be classified as neoclassical. In posing this challenge, Lawson (2013: 951) aims to address the 'debilitating' stand-off between orthodox and heterodox modellers who share an open-system ontology, and to do this by arguing for attention to methodological issues.

Lawson had earlier effectively equated heterodoxy with critical realism, defining it as follows: 'it is an appraisal that mathematical methods are mostly inappropriate to social analysis that ultimately underpins the heterodox opposition. In short, I am contending that the essence of the heterodox opposition is ontological in nature' (Lawson 2006: 493). But he proceeded to note that this social ontology is often implicit. In this more recent article Lawson (2013) argues that the cost of not making heterodox ontology explicit has been that the implications for methodology in many cases have not been taken on board:

'In fact, a good deal of sustained heterodox research is couched in conceptual frameworks consistent with the sort of causal-processual ontological conception just described. All too often, however, this goes hand in hand with a lack of realisation that methods of mathematical modelling require formulations that are in severe tension with this ontology' (Lawson 2013: 957)

A particular constituency of heterodox economics to whom this argument is relevant is those who see philosophical and methodological argument as a distraction; of these, many may not in fact use orthodox methodology, but the challenge to them too is to be methodologically aware, and to articulate and defend one's philosophical and methodological position. The argument which has long been addressed to mainstream economists by Lawson (among others) on the importance of philosophical and methodological awareness, is here being addressed also to heterodox economists. 
The specific argument that many heterodox economists are 'neoclassical' is challenging, and is more difficult for the reader to address because of the absence of concrete examples. We will address it here first in general terms, by focusing on the whole business of classification. We will explore the issues raised by classification being used as an epistemological tool, and its further roles with respect to ontology and as a rhetorical tool. These issues are particularly important for critical realism because of its stance on boundaries, and even more important given Lawson's adoption of Veblen's term for mainstream methodology: 'taxonomic'. In order to address these issues, we then consider Lawson's argument against the backdrop of the Cambridge tradition as a way of trying to make the issues more concrete.

\section{The nature and role of classifications of economics}

Lawson's three-way classification of economics is novel, compared to the conventional two-way classification between mainstream/orthodox economics and heterodox economics. It encourages reflection on the nature of all such classifications. In particular there seems to be a tension between the urge to classify (most clearly in the critical realist version of the distinction between closedsystem and open-system approaches), implying boundaries, and the critical-realist form of opensystems thinking which aims to avoid thinking in terms of boundaries. There is a substantive question as to whether the boundaries Lawson sets up by his categorisation are illuminating or whether they gloss over the possibility of other categorisations (such as theoretical content; see Fine, this volume). But we focus here on the prior question as to the function and implications of classification itself, which applies also to the previous two-way classification (see further Mearman 2012).

The urge to classify is the key defining characteristic of what Foucault $(1966,1969)$ called the classical episteme, or the age of representation. Classification arose from a separation (atomisation) of elements of what had previously, in the age of resemblance, been understood as parts of an organic whole (Vigo de Lima 2010). While in the age of resemblance knowledge was drawn from history and the emphasis was on connections, in the age of representation knowledge was regarded as universal and the emphasis was on distinctions; the resulting taxonomies were based on resemblance within categories, but distinctions between them. Tellingly, Foucault identified Hume and Smith as being on the cusp of the transition from the age of resemblance to the modern episteme, the age of representation, i.e. as retaining aspects of the older episteme (see further Dow 2009). Thus for Smith (1795) new theories arise from seeing new patterns among observed phenomena, i.e. the making of new connections in the imagination (Loasby 2003). But, rather than theoretical patterns being taxonomic, their value was primarily psychological and their form could be expected to change according to context: knowledge was provisional, in that further new patterns might emerge as history unfolded. But as the age of representation proceeded and classical economics developed, the tendency to seek universal theories became more marked and Hume and Smith's approach was largely misunderstood from that new perspective. ${ }^{3}$

\footnotetext{
${ }^{3}$ Indeed this misunderstanding persisted in the early accounts of critical realism, such that the resemblances between critical realism and Hume were not recognised (Dow 2002).
} 
Some classification is inevitable - it is inherent in language itself. But Foucault referred to different conceptions of classification, which can help us understand Veblen's depiction of the mainstream/classical approach as 'taxonomic' as corresponding to Foucault's 'classical' representation by means of classification. The categories of the age of resemblance were more fluid, evolving over time, and the distinctions were more porous and vague, corresponding to the 'modern' approach to classification discussed by Mearman (2012). It also corresponds to Keynes's epistemology, where vagueness was a virtue of the human logic he developed to address an open system (Coates 1996, Davis 1999). Lawson (2013: 951) does note that there can sometimes be virtue in 'loose' use of terminology ('(lexical) ambiguity'). Nevertheless the purpose of the article is to offer a clear, consistent category of neo-classical economics for general application:

' $[\mathrm{F}] \mathrm{ew}$ categories remain entirely fixed in their meaning over time. However there is a sense in which those that prove helpful evolve systematically in the light of new understandings, changing conditions and evolving related needs. This is a case of (the broader notion of) developmental consistency...' (Lawson: 2013: 952).

Thus Lawson draws on Veblen for a category for modern application. He aims for precision in his definition of neoclassical economics on the grounds that loose use of the term has inhibited understanding. This precision of categorisation is a characteristic of the dualistic thinking typical of mainstream economics (Dow 1990); Lawson seeks to introduce a tripartite division to replace the orthodox-heterodox dual, but the critique of dualism can apply equally to three 'allencompassing, mutually-exclusive categories with fixed meanings' rather than two. In developing and refining the concept of duals, Mearman (2005) criticises the critical realist form of the closedsystem/open-system dual on grounds which cut across Lawson's (2013) argument. Thus Davis (2009) argues against the use of fixed categories for economics, while Mearman (2011) argues against the 'rhetoric of distinction'. The closed-system/open-system distinction need not in fact be dualistic. Chick and Dow (2005) consider closed and open systems in non-dualistic terms by setting out the conditions which all have to be met by a closed system, while there is a range of possibilities for systems to be open because any one condition (or combination of conditions) has not been met. Mearman suggests that a useful approach would be to classify along a spectrum between poles. ${ }^{4}$

As an open-system thinker, we would expect Lawson to employ categories in the sense of the age of resemblance, i.e. categories which are vague, evolving and whose boundaries may shift over time. Certainly there has been evolution and the identification of new boundaries in the form of his exploration of Veblen's understanding of neoclassicism as an additional category. But the classification of these boundaries is anything but vague - it is crystal clear in the distinction between a closed-system ontology and an open-system ontology. Further it is a new classification which, rather than being mutable, can be applied across the history of heterodox economics as well as orthodox economics. It is a continuing refrain from orthodox economists in response to heterodox critiques that the mainstream has evolved in ways that are not being accounted for. Yet Lawson has always argued persuasively that his critique continues to hold. Has he in fact developed a taxonomy of economics?

\footnotetext{
${ }^{4}$ Given the different ways in which open systems do not satisfy the conditions for a closed system, classification
} may involve a range of dimensions. 
The key distinction for Lawson is between theorising which is consistent with open-system social reality and orthodox theorising which is only consistent with a closed-system reality (which Lawson, as a heterodox economist, argues is a fiction). The open-system/closed-system classification is treated as an absolute, i.e. taxonomic; only once the distinction (with its methodological implications) is recognised, as Lawson advocates, will economics conform to a heterodox-orthodox duality. The distinction is maintained by Lawson (2004) in response to the argument that differences between heterodox schools of thought derive from (open-system) ontological differences within a non-dualistic structure (Dow 2004). Nevertheless, while Lawson aims for philosophical precision with respect to the definition of heterodox economics as a whole, he employs non-taxonomic categorisation in his treatment of schools of thought within heterodox economics, defining them in a loose, open-ended way in terms of 'ontological commitment'.

Where the ontological difference between orthodoxy and heterodoxy bites is at the methodological level. The methodological implication of a closed-system approach is the reliance, indeed insistence, on deductive mathematical formulation of theory amenable (even if only in principle) to empirical testing. The ontological implication is that the economy is characterised by event regularities which are the manifestation of universal laws. The focus of Lawson (2013) is the argument that some heterodox economists adopt this methodological stance in spite of espousing an open-system ontology. Lawson has been careful to argue (as did Keynes) that a pluralistic, open-system methodology can include mathematics. It is the insistence that arguments be expressed mathematically, and that this mathematics have a deductivist structure (built on supposedly universally-true axioms), which is problematic because such formulations cannot correspond to an open-system reality. This is the key inconsistency - between theorising and reality - which critical realism addresses.

But mathematics can be used for partial analysis; a mathematical model is a closed system in the sense that only certain variables are considered and their interrelationships assumed to take a particular form. But the boundaries of the closed system can be mutable, in application to different contexts, and vague, allowing a range of meanings (as in 'the' rate of interest, for example). Accordingly the assumptions are likely to differ from one partial analysis to another, standing in the way of a deductive, axiomatic structure. Keynes advocated mathematics only for expressing partial logical arguments contributing to a wider analysis, but not for quantification, and certainly not for quantitative prediction.

But, if we are talking about insistence on deductivist mathematics and the extent to which an argument is mathematical and deductivist, we are getting away from absolute distinctions and into matters of degree. There seems to be a parallel between an extension of Lawson's discussion of ontology and Keynes on probability; in the latter case, the earlier understanding of Keynesian uncertainty in dualistic terms relative to certainty has given way to a more complex understanding of shifting degrees of uncertainty between the poles of certainty and complete ignorance. ${ }^{5}$ Is it still

\footnotetext{
${ }^{5}$ Again, the range may span different dimensions, i.e. not necessarily be linear.
} 
satisfactory to understand closed-system theorising and methodology in dualistic terms, or is it time to move on? Again it could be argued that it is an empirical question how far mainstream economists and heterodox economists insist on deductivist mathematical formulations of theory. But again for Lawson it would be a matter of definition: where this insistence is associated with a closed-system ontology we have orthodox economics, where it is associated with an open-system ontology we have neoclassical economics.

How far mathematical formulations account for the full argument could also be seen as an empirical question. But to consider how far this could be a matter of definition raises issues with respect to the structure of argument, for which we turn now to questions of rhetoric.

\section{Classification and Rhetoric}

The rhetoric literature has provided empirical evidence on the form and content of argument in relation to professed methodology (Klamer 1983 and McCloskey 1985 were the pioneering texts in modern times). In particular, McCloskey drew the distinction between the (closed-system) official discourse of mainstream economics and the (open-system) unofficial discourse. The evident need for this unofficial discourse demonstrates the inconclusive nature of closed-system argumentation, consistent with an open-system ontology (and evident similarly in the failure of the Bourbaki project to build a complete, closed mathematical system). Even in articles apparently relying on formal, deductivist reasoning, other forms of reasoning are shown to be used as rhetorical devices, designed to persuade as to the meaning and credentials of the formal argument. It may be that awareness of the range of methods actually employed informally by mainstream economists has allowed them to brush off accusations of closed-system thinking. Lawson (2013) has now addressed the incidence of a tension between a professed open-system ontology and closed-system methodology among heterodox economists as well as orthodox economists. But the rhetoric literature has already pointed to a tension among mainstream economists between a professed closed-system methodology and an open-system methodology in practice. This is a tension within methodology, which differs from the tension Lawson identifies with neoclassical economics, and follows from the need to theorise, communicate and persuade.

While the official discourse of orthodox economics purports to rely solely on formal modelling, it is clear in the official discourse of heterodox economics that formal modelling is only one among many methods employed in a pluralist methodology. The distinction between official and unofficial discourse in orthodox economics is not apparent in heterodox economics, since any formal mathematical reasoning tends to be only a contributor to argument. The other factor relates to the sociology of the discipline which enforces closed-system methodology in the official discourse of economics as a whole. This sociology is critical for the type of knowledge generated, determining the methodology employed by publications in 'leading' journals and in funded research, and thereby hiring practices and education. Thus the official mainstream discourse is propagated, and provides the context for heterodox economists and their methodology.

Rhetorical considerations are important for any discussion of classification, and particularly any discussion of the meaning of neoclassicism and the term's fall from favour. Identifying mainstream 
economics as 'neoclassical' rather than 'economics' had implied a critical stance. I was told some time ago by a leading mainstream economist that he stopped reading anything once the term 'neoclassical' turned up because he assumed it would be critical. Now it is a matter for debate whether heterodox economists should use the term 'mainstream' or 'orthodox' because of the different rhetorical force of each term.

Lawson's own work can be analysed from a rhetoric perspective. There is no question that Lawson has been tremendously persuasive among heterodox economists, convincing a high proportion about the importance of social ontology and its implications for methodology. It is inherent in Lawson's philosophical position that theorising cannot yield law-like truths, but rather expresses powers operative in generative mechanisms, such that persuasion is an integral element in successful argument. As Keynes ([1934] 1973: 470, emphasis in original) put it:

In economics you cannot convict your opponent of error, you can only convince him of it. And, even if you are right, you cannot convince him, if there is a defect in your powers of persuasion and exposition or if his head is already so filled with contrary notions that he cannot catch the clues to your thought that you are trying to throw at him.

It has been argued above that Lawson builds up a clear-cut distinction between closed and opensystem approaches which seems somewhat inconsistent with his own non-taxonomic thinking. But we have to consider how far this distinction is being employed for rhetorical force and accounts for critical realism's success. There has over the last few decades been a steady building-up of awareness among heterodox economists that their methodological approach is different from orthodoxy and that there are good reasons to justify that difference. Critical realism has provided a substantial philosophical foundation for this difference. How far has it been persuasive by posing a duality between orthodoxy and heterodoxy, supporting heterodoxy's growing sense of identity?

Some time ago, Lawson (2002) explicitly addressed the fact that his philosophy is expressed in a rationalistic manner which seems at odds with critical realist philosophy:

[I] t must also be acknowledged that (essentially ontological) arguments of the sort sketched here and elaborated elsewhere (e.g., Lawson, 1997) are somewhat rationalistic, and that this especially always carries dangers. Although such arguments as I defend currently seem (to me) to be as sustainable as others with which they compete, they are of course fallible and partial, and may yet turn out to be quite dramatically wrong, at least in certain significant respects. It may be found that, on occasion, aspects of the social world after all approximate a closure, for example. Or new mathematical methods may yet be devised which are found to be (more) appropriate to open systems. Who knows? (Lawson 2002: 80-81).

The rhetorical aspect within the current social structure of the discipline is then made explicit:

The reason (rationalistic) ontological analysis remains so important at this juncture is just that such an evolutionary scientific process is currently blocked. Or rather the environment of selection is so determined that, for the time being, any flourishing (that is, widespread) 
practice must be of a mathematical form. Real progress, that is, in social understanding, is, in other words, undermined by the pervasive insistence in faculties of economics that the only (or almost only) permitted form of activity involves the wielding of mathematical models. It is this dogma, this constraint on evolutionary progress in knowledge, that makes the input from (somewhat rationalistic) ontology at this point so important (Lawson 2002: 81).

Lawson (2013: 979) makes explicit the rhetorical case for focusing on neoclassical economics as a vehicle for drawing attention to inconsistencies between ontology and methodology:

'My aim here, in reporting my findings, is, in the end partly rhetorical, namely, to point out that if coherence in use is required, then according to the seemingly most sustainable conception, many of those who use the term 'neoclassical' as an ill-defined term of abuse can be viewed ultimately as engaged in unwitting self-critique. But I am hoping, more fundamentally, that it is enough in this manner to communicate (in a yet further way) that in modern economics there prevails largely unrecognised a basic tension between ontology and method, one that hinders serious attempts to overcoming the real problems of the discipline.'

In using the term 'tension' (interchangeably with 'inconsistency'), Lawson may be intending to signal the meaning of consistency which accords with open-system thinking. While 'inconsistency' has a clear (classical logic) meaning within a closed system of thought, it is harder to identify within an open system of thought (Dow 1990, 2014). When does difference, e.g. as between different strands of partial analysis, reveal a regrettable logical inconsistency, and when does it simply reflect the nature of a pluralist methodology? Even within orthodox economics, Weintraub (2002) argues that applied mathematics (characteristic of much of mainstream economics) inevitably involves inconsistencies which pure mathematics (the method of pure mainstream theory) can avoid.

For Lawson the critical inconsistency is between methodology and reality. But this may not be so straightforward either. We therefore need to explore further what we need to look for when seeking out inconsistencies within otherwise apparently heterodox economics. Do the heterodox economists Lawson has in mind insist on deductive mathematical reasoning for their official and unofficial discourse, and is it regarded as sufficient for economic argument? As a limited empirical exercise, we turn now to the Cambridge tradition in economics for evidence on economic methodology and its philosophical underpinnings.

\section{Classicism and neoclassicism at Cambridge}

The difficulty in applying the classification suggested by Lawson to any economist or group of economists is evident as soon as we attempt to put it into practice. The examples in the history of thought literature are legion of disagreements as to how to interpret and categorise the methodological approach of leading figures. The history of economics at Cambridge is an interesting case in point, not least because of Martins's (2013) exercise in pulling out features in the history of economic thought at Cambridge which allow him to identify a Cambridge tradition 
stemming from Ricardo, through Marx, and built up by Marshall, J M Keynes, Sraffa, Sen, and (at the philosophical level) by Lawson's critical realism. The argument is that there has been a consistency of approach, applied at different levels (see further Dow forthcoming). Yet Lawson, following Veblen, identifies the classical approach, on which the mainstream has built, with Ricardo. Martins (this volume) challenges this treatment of Ricardo and classical economics. The categorisation of Marshall is equally contentious; while Martins, following Harcourt ([2003]2012: 201), sees Marshall as the initiator of the Cambridge tradition which includes critical realism, Lawson follows Veblen in categorising him as neoclassical.

For Lawson, the litmus test is whether or not an economist insists on formal deductivst mathematics and regards such argument as sufficiently demonstrative: the characteristics of a closed-system methodology. The view of formal mathematical argument being necessary and sufficient follows from deductivism. But it is so in the sense that it is regarded as a superior 'language' by which to express deductive logic. We know from the history of mathematics and from the economic rhetoric literature that mathematical argument is not in fact sufficient; it is necessarily accompanied by other forms of argument. This renders formalist deductivism incoherent as a positive methodology. Where the insistence on formal mathematical treatment has greatest impact is rather, as Lawson points out, in its negative form: the view that nonmathematical argument does not meet methodological requirements for good theory.

There has been a common thread within Cambridge of objections to this view, beginning with Malthus's critique of Ricardo's methodology on ontological grounds (Cremaschi and Dascal 1996), such that Malthus would seem to fit into the heterodox category better than Ricardo. Marshall explicitly demoted the mathematical method by confining mathematical derivations to footnotes. He wrote to his protégé, J N Keynes, as follows: 'I take an extreme position as to the method \& scope of economics. In my new book I say of methods simply that economics has to use every method known to science' (emphasis in original, as quoted by Groenewegen 1995: 415). Yet $\mathbf{J}$ N Keynes himself arguably actively (even if inadvertently) promoted deductivism in the Millian tradition (Deane 1983, 2008). Veblen identified Marshall and J N Keynes as the best (in the sense of least contradictory) examples of neoclassical economists by his definition, both displaying open-system ontological positions while using the deductive mathematical method. But this is inconsistent with what Marshall himself said about his methodology. He certainly facilitated others in building up a deductive mathematical structure, but he himself did not insist on it. This unresolved contradiction in Marshall has long been understood to explain his inability to produce the second volume of the Principles. Indeed Lawson's hesitation to apply his own criterion strictly is evident in the following passage:

'In short, a feature of contributions of both Keynes and Marshall that is significant with regard to the sorts of issues that interest Veblen is a tension bordering upon inconsistency. It is a tension between method and ontology/metaphysics (or more accurately between the ontological presuppositions of taxonomic method and a causal-processual social ontology)’ (Lawson 2013: 968, emphasis added).

In contrast to his father and to Marshall, J M Keynes, consistently and repeatedly discussed the problems with insistence on deductivist mathematical formulation, on ontological grounds, in a manner consistent with the methodology he himself employed. Keynes therefore fits clearly into 
the heterodox category and indeed his philosophy has provided inspiration for critical realism. Yet he used mathematical expression at times, as an exercise in logic rather than with a view to quantification. The aim was not to establish laws (confirmed by repeated instances) since the organic nature of the socio-economic system could not yield them. Similarly he did not rule out quantitative analysis as such but rather, in his debates with Tinbergen, explored the conditions which would need to be met in order for econometric analysis to be warranted (O'Donnell 1997).

But how are we to classify those who came after Keynes? Arguably the 'Circus' around Keynes found it difficult to break away from Pigovian deductivism (Ambrosi 2003). For example, even by the time of the capital controversies, Joan Robinson, appeared to accept the mainstream positivist methodology in that she aimed her critique at the realism of assumptions and the internal consistency of its logic. The controversy came to be epitomised for many by the 'reswitching' problem which demonstrated by means of deductivist mathematical reasoning that capital and its return need not be inversely related (Harcourt 1972). Similarly Sraffa expressed his critique of mainstream economics in terms of a formal mathematical system, albeit one which differed from mainstream marginalist analysis and which aimed to avoid fictional assumptions (Velupillai 2008). Since both Robinson and Sraffa professed an open-system ontology; are they therefore neoclassical by Lawson's definition? On the other hand, while Hahn clearly employed a formal deductivist mathematical methodology, he could also be said to have had an open-system ontology in (at times) arguing that formal general equilibrium had no real-world counterpart; the mathematics was to be a matter of logic rather than quantification (see e.g. Hahn 1985). His mathematics was quintessentially deductivist, but was he too neoclassical? ${ }^{6}$

It is clearly important to explore what we mean by 'deductive mathematics'; Martins (2013) in particular makes much of the significance of different types of mathematics, beginning with Newton. For Newton it was important that mathematical argument correspond to real experience, building on common sense understandings, so he relied on classical geometry as separate from arithmetic. Rather than separating induction and deduction, however, he combined the two in a process of abduction whereby hypotheses were derived from the operation of the mind on observation and then exposed to further observation. The result was provisional principles rather than universal laws. In contrast Descartes applied deductive logic to fictional concepts (such as irrational numbers, infinity and points), to be tested against the enumeration of instances. While Newton relied on classical geometry as separate from arithmetic, Descartes combined the two in analytical geometry (Martins 2013: ch. 5). While for Newton geometrical argument related directly to real experience, the calculus did not necessarily have any real counterpart.

J M Keynes was to develop further the use of mathematics within a system of abductive logic, eschewing concepts without real-world correspondence, while the mainstream employed logical positivism with its clear separation between mathematical deduction, from unverified premises about rational optimising behaviour, and empirical testing. Keynes's deductions were applied rather to assumptions which were simplifications (based on 'stylised facts') rather than fictions (e.g. the falling MPC). As such the conclusions reached were provisional, depending on the persistence of the simplified relation, and conditional on other aspects of the system. The key was

\footnotetext{
${ }^{6}$ Could it even be that Becker was heterodox? Heckman (2015) argues that Becker used the abductive, rather than deductive, method and, in effect, that he employed an open-system ontology.
} 
that an abductive approach is not capable of yielding a complete deductive system, so inevitably mathematical argument is bound to be only one of many methods to be used. Any formal model, even one which deduces a partial argument rather than a general argument on the basis of assumptions, is temporarily closed. But the point of abductive reasoning is that this closure is temporary, yielding only provisional conclusions which may change as the assumptions may be replaced. It made no sense in abductive logic to insist on mathematical expression in general, or to regard it as sufficient for argument. This stance has been continued at Cambridge, notably by Harcourt (1996), with his 'horses for courses' approach and by Lawson with his critical realism.

But we have seen that what has been identified as a(n implicitly heterodox) Cambridge tradition seems to have involved significant components of what Lawson defines as neoclassical economics. Any such discussion of a body of research which has evolved over time, subject to a range of influences, is bound to be controversial such that there is scope for much disagreement as to what exactly is neoclassical in the Cambridge tradition. In a way that is the point. The triad has rhetorical force and poses good questions, but in such a categorical philosophical way that it is difficult to operationalise.

\section{Conclusion}

By opening up debate on the category of neo-classical economics, a coherent framing has been offered for discussing such subjects as the Cambridge tradition in economics, even though any conclusions on specific economists can only arise out of debate, and possibly not even then. More widely, by drawing attention to ontological issues, Lawson invites further debate as to their implications, the nature of closed and open systems, and so on. I have engaged in similar exercises, with the same aim of promoting methodological awareness. In this commentary my aim has been to make a further contribution to the debate by approaching this new classification with a different framing - responding in kind to an exercise in open-system analysis.

This different framing has aimed at specific application of Lawson's new categorisation, resulting in a range of questions. In seeking to apply Lawson's classification to modern heterodox economics more widely, is it modelling that is an indicator of neoclassicism by Lawson's definition, or only deductivist modelling based on fictional assumptions and/or deductivist modelling as sufficient for argument? How far is the injunction against deductivist modelling open to misinterpretation as an injunction against all modelling? Mearman (2005) argues that the critical realist presentation of orthodoxy-heterodoxy as mutually-exclusive has discouraged heterodox economists from employing mathematical modelling when it would in fact have been a useful contributor to theorising. By the same token, how far can the mainstream reject critical realist arguments more readily when these arguments are (mis?)interpreted as an anti-mathematics position?

Good rhetoric is persuasive; it appeals to many aspects of epistemology, including reason and evidence. Just as rational economic man is a fiction, so mainstream economists build knowledge on more than narrow rational argument, inevitably opening up possibilities for contradiction which, in an open system of thought, need not necessarily be of concern (only a matter for argument and debate). The important contradiction for a policy-related subject to avoid is that with reality. But that too is a matter for argument if (as I would argue) there are different understandings of open-system reality. Where Lawson (2002) himself has admitted he needs to be careful is the 
scope for contradiction in using rationalist argument to counter rationalism. But, as Morgan (2014: 22) suggests, the rhetorical purpose here may well be more disruption than persuasion: 'every now and then, it is better to be the Sex Pistols than The Carpenters'. The way in which 'neoclassical' heterodox economists take the argument will be different from mainstream reactions. But disruption needs to be followed through with further development of what exactly in particular modelling exercises is incompatible with open-system ontology, and whether the answer varies depending on the type of open-system ontology under consideration.

Having launched this salvo at economics normally regarded to be heterodox, Lawson proceeds to suggest that the term 'neoclassical' no longer be used, not least because a philosophical inconsistency is a poor basis for a school of thought. In the end, the message is the one consistently pushed by Lawson, that all economists should reflect on their ontology and consider how far it is consistent with their epistemology and methodology. The aim is to root out the type of problematic inconsistencies which are apparent in orthodox economics, but which Lawson implies are evident also in heterodox economics. In other words, this time the message is being addressed explicitly to heterodox economists as well as orthodox economists. The onus is on all economists to be able to justify their methodology; rather than accepting automatically the current orthodox presumption in favour of formal mathematical modelling, economists should be able to justify their use (and choice) of mathematics on a case-by-case basis. If heterodoxy is distinguished by its open-system ontology and therefore its open-system epistemology and methodology, it is important for heterodox economists to be aware of this and able to justify their practice accordingly.

\section{References}

Ambrosi, G M (2003) Keynes, Pigou and the Cambridge Keynesians. London: Macmillan.

Chick, V and Dow, S ([2005] 2012) 'The Meaning of Open Systems', Journal of Economic Methodology, 12: 363-81, reprinted in S Dow, Foundations for New Economic Thinking: $a$ collection of essays. London: Palgrave Macmillan, pp.178-96.

Coates, J (1996) The Claims of Common Sense. Cambridge: Cambridge University Press.

Cremaschi, S and Dascal, M (1996) 'Malthus and Ricardo on Economic Methodology', History of Political Economy 28(3): 475-511.

Davis, J B (1999) 'Common Sense: A Middle Way between Formalism and Post-structualism?', Cambridge Journal of Economics 23: 503-13.

Davis, J (2009) 'The Nature of Heterodox Economics', in E Fullbrook (ed.), Ontology and Economics: Tony Lawson and his Critics. London: Routledge, pp. 83-92.

Deane, P (1983) 'The Scope and Method of Economic Science', Economic Journal, 93 (March): $1-12$. 
Deane, P (2008) 'Keynes, John Neville (1852-1949)', in S N Durlauf and L E Blume (eds), The New Palgrave Dictionary of Economics, vol. 4. London: Palgrave Macmillan, pp. 725-6.

Dow, S (1990) 'Beyond Dualism', Cambridge Journal of Economics, 14.2.143-158, reprinted in Foundations for New Economic Thinking. London: Palgrave Macmillan, 2012, pp. 52-71.

Dow, S (2002) 'Historical Reference: Hume and Critical Realism', Cambridge Journal of Economics, 26 (6): 683-97.

Dow, S (2004) 'Reorienting Economics: Some Epistemological Issues', Journal of Economic Methodology, 11 (3): 307-12.

Dow, S (2009) 'Hume and the Scottish Enlightenment - Two Cultures', Revista de Economia, 35(3): 7-20.

Dow, S (2013) 'Mark Blaug on Formalism and Reality: the case of behavioural economics', Erasmus Journal for Philosophy and Economics, 6 (3), 2013: 26-43.

Dow, S (2014) 'Consistency in Pluralism and Microfoundations', PKSG Working Paper 1408.

Dow, S (forthcoming) 'Cambridge's contribution to methodology in economics' in R Cord (ed.), The Palgrave Companion to Cambridge Economics. London: Palgrave Macmillan.

Fine, B (forthcoming) 'Neoclassical Economics: An Elephant is not a Chimera But Is a Chimera Real?', in J Morgan (ed.), What is this 'school' called neoclassical economics? Debating the issues. London: Routledge.

Foucault, M (1966/1991) The Order of Things. London: Routledge.

Foucault, M (1969/1992) The Archaeology of Knowledge. London: Routledge.

Groenewegen, P (1995) A Soaring Eagle: Alfred Marshall 1842-1924. Cheltenham: Edward Elgar.

Hahn, F H (1985) 'In Praise of Economic Theory', The 1984 Jevons Memorial Fund Lecture. London: University College.

Harcourt, G C (1972) Some Cambridge Controversies in the Theory of Capital. Cambridge: Cambridge University Press.

Harcourt, G C ([1996]2001) 'How I Do Economics', in S G Medema and W J Samuels, eds, How Do Economists Do Economics Cheltenham: Edward Elgar, pp. 93-102. Reprinted in 50 Years a Keynesian and Other Essays. London: Palgrave Macmillan, pp. 323-33.

Harcourt, G C ([2003]2010) 'The Cambridge Economic Tradition', in J E King (ed.), The Elgar Companion to Post Keynesian Economics. Cheltenham: Edward Elgar, pp. 44-51. Reprinted in The Makinjg of a Post-Keynesian Economist. London: Palgrave Macmillan, pp. 201-10. 
Heckman, J J (2015) ‘Gary Becker: model economic scientist’, IZA Discussion Paper 8827.

Keynes, J M ([1934] 1973) 'Towards the General Theory', The General Theory and After. Part I: Preparation. Collected Writings vol. XIII. London: Macmillan, for the Royal Economic Society, pp.337-653

Klamer, A (1983) Conversations with Economists. Totowa NJ: Rowman and Allanhold; also published as The New Classical Macroeconomics. Brighton: Wheatsheaf, 1984.

Lawson, T (1997) Economics and Reality. London: Routledge.

Lawson, T (2002) 'Mathematical Formalism in Economics: what really is the problem?', in P Arestis, M Desai and S Dow (eds), Methodology, Microeconomics and Keynes. London: Routledge, pp. 73-83.

Lawson, T (2004) 'Reorienting Economics: On heterodox economics, themata and the use of mathematics in economics', Journal of Economic Methodology 11 (3) 229-40.

Lawson, T (2006) 'The nature of heterodox economics', Cambridge Journal of Economics 30: 483-505.

Lawson, T (2009) 'The current economic crisis: its nature and the course of academic economics', Cambridge Journal of Economics, 33(4): 759-77.

Lawson, T (2013) 'What is this "school" called neoclassical economics?', Cambridge Journal of Economics, 37: 947-83.

Loasby, B J (2003) 'Closed Models and Open Systems', Journal of Economic Methodology 10: 285-306.

Martins, N (2013) The Cambridge Revival of Political Economy. London: Routledge.

Martins, N (2015) 'What is this 'school' called neoclassical economics? Classicism and neoclassicism in historical context', in J Morgan (ed.), What is neoclassical economics? London: Routledge, pp. 149-67.

McCloskey, D N (1985) The Rhetoric of Economics. Brighton: Wheatsheaf.

Mearman, A (2005) 'Sheila Dow's concept of dualism: clarification, criticism and development', Cambridge Journal of Economics 29: 619-34

Mearman, A (2011), 'Pluralism, Heterodoxy and the Rhetoric of Distinction', Review of Radical Political Economics 43(4): 552-561.

Mearman, A (2012) “"Heterodox economics" and the problems of classification', Journal of Economic Methodology 19 (4): 407-24. 
Morgan, J (2014) 'What's in a name? Tony Lawson on neoclassical economics and heterodox economics', Cambridge Journal of Economics, doi: 10.1093/cje/beu041.

O’Donnell, R (1997) 'Keynes and Formalism', In G C Harcourt and P A Riach (eds.), A 'Second Edition' of the General Theory. London: Routledge, pp. 131-65.

Smith, A ([1795] 1980) 'The History of Astronomy', in W L D Wightman (ed.), Essays on Philosophical Subjects. Oxford: Oxford University Press.

Velupillai, K V (2008) 'Sraffa's mathematical economics: a constructive interpretation', Journal of Economic Methodology, 15 (4): 325-42.

Vigo de Lima (2010) Foucault's Archaeology of Political Economy. London: Palgrave Macmillan. Weintraub, E R (2002) How Economics became a Mathematical Science. Durham NC: Duke University Press. 